\title{
DIAGNÓSTICOS PSICOSSOCIAIS DE CRIANÇAS E ADOLESCENTES NA FEBEM DE SÃO PAULO
}

\author{
RITA DE CÁSSIA PEREIRA LIMA \\ Professora no Programa de Estudos Pós-Graduados em Serviço Social da PUC-SP \\ Membro do Núcleo de Estudos e Pesquisa sobre a Criança e o Adolescente - NCA - PUC-SP
}

\section{RESUMO}

Oobjetivo deste artigo é refletir sobre como os profissionais das equipes da FEBEM-SP elaboram diagnósticos psicossociais que definem a situação das crianças e adolescentes atendidos pela instituição. Será enfatizado o papel ambíguo, arbitrário e ineficiente dessa tarefa técnica dentro dos dispositivos jurídico-institucionais de atendimento socioeducativo a esses individuos. Oreferencial teórico privilegia um enfoque sociológico dos diagnósticos a partir dos trabalhos de Robert Castel, para em seguida abordar as práticas diagnósticas com base na teoria interacionista do desvio e no estudo das representações. Essa análise será ilustrada pelos discursos dos profissionais das equipes, em que os diagnósticos aparecem relacionados às idéias que eles fazem da criança e do adolescente, da FEBEM e da sua própria prática. No seu conjunto, esse texto explicita a fragilidade dos relatórios escritos, decorrente do funcionamento institucional e da subjetividade dos especialistas, dificultando a melhora da qualidade do atendimento da FEBEM-SP.

FEBEM-SP - CASTEL, Robert-INTERDISCIPLINARIDADE-DIAGNÓSTICO-RELAÇÓESSOCIAIS

\section{ABSTRACT}

PSYCHOSOCIAL DIAGNOSIS OFCHILDRENANDADOLESCENTSIN THEFEBEM-SP(FOUNDATION FOR CHILD WELFARE - SAOO PAULO). The objective of this article is to reflect on how teachers from the teams of the FEBEMSP teams develop their social-psychological evaluations, which define the situation of the children and adolescents attended by the institution. The ambiguous, arbitrary and inefficient roles of this technical task within the juridical-institutional mechanisms for the social and educational care of these individuals will be emphasized. The theoretical framework prioritizes a sociological focus in diagnostics based on the work of Robert Castel, and then approaches diagnostic practice based on the interactional theory of deviation and on the study of representation. This analysis will be illustrated by the discourse of the team professionals, in which the diagnostics appear to come from ideas that they have of the children and adolescents of FEBEM and from their practice itself. In its totality, this text makes the fragility of written reports explicit. This is a result of institutional functioning and the subjectivity of the specialists, making improvement in the quality of care at the FEBEM difficult.

Artigo baseado em tese de doutorado intitulada: O processo de elaboração de diagnósticos sobre crianças e adolescentes "abandonados", "assistidos" e "infratores" pelas equipes interdisciplinares da Fundação Estadual do Bem-Estar do Menor de São Paulo (FEBEM-SP) - Brasil, defendida na Universidade René Descartes - Paris V - Sorbonne, em 1994. O trabalho contou com o apoio financeiro do CNPq. 


\section{OS DIAGNÓSTICOS PSICOSSOCIAIS NO CONTEXTO JUDICIÁRIO-INSTITUCIONAL DA FEBEM DE SÃO PAULO}

O texto apresentado em seguida considera, num primeiro momento, que os diagnósticos' sobre as crianças e adolescentes atendidos pela FEBEM do Estado de São Paulo obedecem a critérios burocráticos e institucionais, em parte necessários, que justificam o funcionamento e as práticas da instituição. Porém, deter-se nessa particularidade, mesmo com base em reflexões críticas, seria apresentar uma visão redutora do fenômeno. $\mathrm{Na}$ realidade, o diagnóstico sobre crianças e adolescentes, predominantemente de classes populares, revela uma percepção das relações sociais influenciada por concepções de sociedade e de justiça social por parte dos especialistas ${ }^{3}$.

Este artigo privilegiará uma análise psicossociológica dos diagnósticos, tentando mostrar como eles traduzem uma avaliação técnico-científica que mascara os valores, a visão de mundo e a história pessoal e socioprofissional das pessoas que os emitem. Longe de ser uma avaliação objetiva, com fins terapêuticos e sociais que possam propor melhoria nas condições de vida das crianças e adolescentes, o diagnóstico acaba não contribuindo para que isso ocorra.

No contexto da FEBEM, em que um grande número de crianças e adolescentes são encaminhados, triados e avaliados diariamente, o diagnóstico se incorpora à dinâmica institucional, tendo mais o papel de legitimar um desvio ou um estigma, na medida em que o diagnóstico se restringe à definição de um perfil psicológico e de uma moralidade. Em geral, a instituição não oferece condições para que sejam realizados estudos individuais detalhados e acompanhamentos dos casos. Dessa forma, as sugestões ou decisões dos profissionais tendem a ser essencialmente influenciadas pela maneira com que eles percebem a criança ou adolescente, pelo tipo de relação que estabelecem com a instituição e pelas suas concepções sobre o próprio trabalho.

Antes de dar prosseguimento a essas reflexões, seria essencial comentar a inserção dos diagnósticos psicossociais no mecanismo institucional, citando dados fundamentais para a compreensão da análise proposta ao longo do texto. Em $1989^{3}$ a FEBEM-SP era consti-

I. Quando se utiliza o termo "diagnóstico", trata-se do documento que deve ser enviado ao Juiz da Infância e Juventude definindo o encaminhamento da criança ou adolescente, por exemplo, a unidades da FEBEM, família, emprego, pensão... Esse texto não visa discutir as diferentes terminologias empregadas para designar essa mesma atividade, como "relatórios", "pareceres técnicos", "laudos" etc.

2. A condição de pobreza que atinge a maioria das crianças e adolescentes atendidos pela FEBEM é o elemento de inspiração deste trabalho. Porém, a realidade socioeconômica brasileira, marcada, principalmente, pelas desigualdades sociais, não será analisada em detalhes, visto que se trata de um tema já bastante discutido em várias pesquisas realizadas na área.

3. A pesquisa de campo para a tese de doutorado que originou esse artigo foi realizada em 1989. Embora as unidades da FEBEM tenham sido modificadas, e algumas desativadas, os diagnósticos para receber, triar e encaminhar crianças e adolescentes são ainda uma prática atual da instituição. 
tuída por três tipos de estabelecimentos: Unidade de Recepção, Unidades de Diagnóstico, Unidades de Encaminhamento. Em regra geral, a trajetória da criança ou adolescente ${ }^{4}$ na fundação acontecia da seguinte maneira:

I. Eram encaminhados à Unidade de Recepção da FEBEM por quatro vias principais: distrito policial, instituições sociais (filantrópicas ou de caridade), família e iniciativa própria. Na unidade eram considerados "infratores" aqueles acompanhados por um Boletim de Ocorrência, "abandonados", os que não possuíam família ou responsáveis, e "carentes" ou "assistidos", os provenientes de famílias sem meios socioeconômicos para mantê-los.

A Unidade de Recepção mantinha dois tipos de estabelecimentos: Pronto Atendimento e Unidades de Triagem. No Pronto Atendimento onde eram recebidas todas as crianças e adolescentes encaminhados à FEBEM, o Juiz da Infância e Juventude determinava que para cada caso fosse elaborado um parecer técnico, no prazo de 72 horas, pelos assistentes sociais e psicólogos. Nas unidades de triagem, compostas por seis pavilhões e destinadas somente a meninos infratores de 14 a 18 anos, a determinação era de que se elaborasse um estudo "biopsicopedagógico e social" no prazo de dois meses. Esse estudo, confiado a uma equipe interdisciplinar, constituída de assistentes sociais, psicólogos, psiquiatras e pedagogos, deveria conter uma sugestão, por exemplo: retorno à família, à cidade ou região de origem, encaminhamento às Unidades de Diagnóstico ou Encaminhamento da própria FEBEM, encaminhamento a instituições conveniadas com a FEBEM, a pensões ou hospitais (psiquiátricos ou gerais).

II. Conforme as decisões da Unidade de Recepção e de acordo com o Juiz da Infância e Juventude, as crianças poderiam ser encaminhadas às Unidades de Diagnóstico ou Encaminhamento da FEBEM, segundo sua classificação ("abandonado" ou "infrator"). O papel das Unidades de Diagnóstico era o mesmo dos pavilhões de triagem da Unidade de Recepção: realização de um estudo "biopsicopedagógico e social" por uma equipe interdisciplinar, no prazo de dois meses. As sugestões para cada caso também poderiam ser as mesmas citadas anteriormente.

III. As equipes das Unidades de Recepção e Diagnóstico, por sua vez, se apoiavam nos estudos "biopsicopedagógicos e sociais" realizados pelas Unidades de Triagem e Diagnóstico para propor e acompanhar os programas de tratamento,

4. Foram considerados todas as crianças e adolescentes encaminhados à FEBEM-SP, independentemente da classificação atribuída ("abandonado", "assistido", "infrator"...), porque todos são submetidos a um diagnóstico psicossocial por determinação do juiz. 
visando à reintegração da criança ou adolescente. Essas equipes eram compostas por assistentes sociais, psicólogos, psiquiatras, pedagogos, clínicos gerais, pediatras, professores de educação física, dentistas...

De acordo com as exigências judiciárias, esses profissionais deveriam encaminhar ao juiz, no prazo de 30 dias, um estudo de caso e um plano "terapêutico-educacional" para cada criança ou adolescente. A permanência nessas unidades era por tempo indeterminado e as equipes deveriam enviar um relatório semestral ao juiz, fornecendo informações sobre a evolução de cada caso e indicando propostas de liberação ou encaminhamento. As sugestões eram aproximadamente as mesmas indicadas anteriormente, sendo que os "infratores" poderiam ser colocados em "liberdade assistida" e os "abandonados" em empregos na comunidade. ${ }^{5}$

A trajetória da criança ou do adolescente por diferentes instâncias, fundada nos pareceres técnicos, mostra como se opera a dinâmica de atendimento da FEBEM-SP. Seu funcionamento baseia-se fundamentalmente na classificação e seleção de milhares de crianças e adolescentes das classes desfavorecidas, assinalando os que devem ser submetidos à intervenção institucional. Em 1989, a FEBEM registrou 20.366 casos atendidos, não especificando se um mesmo indivíduo foi registrado mais de uma vez (FEBEM, 1989). Nessa época, o total de vagas nos três tipos de unidades (Recepção, Diagnóstico e Encaminhamento) era 4.652. Em 21 de março de 1989 foram registrados 5.585 crianças e adolescentes (FEBEM, 1989) e 5.567 em 30 de novembro (FEBEM, 1989).

Esses dados mostram que a instituição, freqüentemente superlotada, recebe um número de crianças e adolescentes acima de sua capacidade de atendimento. E, por falta de vagas e muita rotatividade, os diagnósticos são geralmente realizados de maneira apressada e sem critérios precisos, determinando aleatoriamente os indivíduos liberados e os retidos para atendimento. Esse contexto leva a uma questão inicial, a qual levanta uma segunda: como as crianças e adolescentes institucionalizados são selecionados, considerando-se o total que chega cotidianamente à FEBEM? Como os atendidos pela instituição são liberados ou encaminhados e, em seguida, substituídos por outros?

Essas reflexões levam primeiramente a uma crítica à dinâmica judiciário-institucional. A instituição não oferece condições para que os diagnósticos sejam realizados com eficácia, incluindo suporte técnico anterior à institucionalização, possibilidade de assegurar um acompanhamento eficiente durante a internação e supervisão após a desinternação. Cerezuelle (1983) introduz essas idéias ao analisar 192 dossiês de jovens atendidos por instituições educativas na França. Para o autor, embora o atendimento socioeducativo exija troca de

5. Algumas dessas determinações foram alteradas com a aprovação do Estatuto da Criança e Adolescente - ECA em 1990. Porém, os relatórios técnicos para encaminhamento das crianças e adolescentes continuam sendo exigidos pelo Juizado da Infância e Juventude. 
informação, redação de relatórios, transmissão de dados, discussão, síntese, trabalho de equipe, definição de um projeto individualizado, avaliação dos resultados obtidos, exame crítico e relação entre profissionais e jovens, os dossiês não revelam todas essas trocas. Geralmente não explicitam um conteúdo técnico-teórico que dê suporte ao atendimento. Cerezuelle afirma:

O processo de colocação, de atendimento e de "trânsito" dos casos acontece sem comunicação da informação técnica ou sobre a base de uma elaboração técnica extremamente pobre de informação, apesar da multiplicação de técnicos em todos os níveis. (Cerezuelle, 1983, p.9)6

Para o autor, o suporte escrito não é rigoroso, completo e preciso, de forma a permitir uma ação socioeducativa individualizada que garanta continuidade e coerência ao longo do tempo. A avaliação acaba se tornando um julgamento do indivíduo e não uma proposta de intervenção com o devido acompanhamento e revisão crítica. Cerezuelle observa que o funcionamento dos dispositivos de atendimento resulta em um formalismo (no sentido de se prender a formalidades) técnico e burocrático. Na realidade, a caracterização dos jovens nos dossiês serve muito mais para a sua colocação em novos estabelecimentos do que para o trabalho a ser realizado com eles no cotidiano. $\bigcirc$ autor coloca os relatórios escritos numa dinâmica contraditória que envolve as exigências da instituição e uma relativa autonomia das práticas profissionais:

As disfunções observadas contém, no nosso ponto de vista, a incompatibilidade entre, por um lado a organização institucional regida segundo uma legitimidade racional legal do tipo burocrático, fortemente hierarquizada com referência a um modelo técnico-experimental, operatório e facilmente objetivável, e, por outro lado, os savoir-faire e as práticas fundadas sobre interpretações e avaliações qualitativas recorrendo inevitavelmente a julgamentos de valor e finalmente a referências éticas. (Cerezuelle, 1983, p. 17)

No caso da FEBEM, apesar do diagnóstico ter a função essencial de responder a uma demanda burocrática e judiciária, o papel das equipes interdisciplinares ultrapassa o de meros executores de tarefas exigidas pelo aparelho judiciário-institucional. As ações e representações desses especialistas também estão presentes nas decisões tomadas a respeito de cada criança ou adolescente. Como mencionam lon-Tricart:

Que seja oral ou escrito, o discurso do trabalhador social é freqüentemente carregado de sentido. Diagnóstico ou rotulação, ele pretende dizer a realidade. E diz se o interesse da criança é ser colocada num estabelecimento ou guardada em sua família. Ele é exortação moral ou persuasão pedagógica, mesmo se quer o esforço permanente para obter a adesão. É o instrumento obrigatório, mas não se tem necessariamente o seu domínio, dessa atividade relacional tão

6. Esta e todas as traduções encontradas nesse artigo foram feitas pela autora. 
Para ilustrar o papel essencial dos diagnósticos psicossociais no funcionamento institucional, serão citados, como ponto de partida, dois exemplos de pareceres encaminhados ao juiz: um sugerindo a liberação do jovem, e o outro, a internação. Quanto ao primeiro caso, elaborado em 1986, trata-se de " $X$ ", um menino de 17 anos encaminhado à FEBEM por roubo. " $X$ " é um reincidente, visto que já tem passagem pela instituição devido a latrocínio. Seguem alguns trechos do relatório, realizado por assistente social, psicólogo e psiquiatra’:

Assistente social:

$X$ fala de sua infância no Norte, até 3 anos de idade, onde aparece um homem que ele não tem claro se realmente tratava-se de seu pai biológico ou padrasto, mas sabe que esse homem o traz para São Paulo e o faz "filho" de uma senhora que ele passa a chamar e obedecer como mãe (...) Fala desta experiência como "ruim" (...) Na relação ora padrasto, ora pai, citando neste momento que acredita ter sido enganado por este homem, que na medida em que deixou de "verbalizar sou seu pai" nunca o quis verdadeiramente, ainda que o criasse. Na convivência com esse casal, $X$ lembra que sua presença era como que imposta, pois nas discussões e nos desentendimentos do casal ele era tido como a causa principal (...) Percebe-se não aceito, passa a fugir de casa e nestas constantes fugas refugia-se nas favelas, descobre um mundo que hoje chama "das ilusões". Na distância do lar, colocando-se à margem do contexto familiar, passa a ser cliente das instituições protetoras de menores da região (...) Houve um dia em que sua permanência na instituição ficou por tempo indeterminado, quando soube por terceiros que seus pais recuaram diante da responsabilidade de tê-lo em sua guarda (...) Centrado no Senhor Y, uma autoridade do Fórum de Santo André, a pessoa que levou-o a uma comunidade crente, contava com 14 anos de idade; e neste espaço protetor, recebeu uma educação permeada na religiosidade, atingindo a $6^{\mathrm{a}}$ série do $\mathrm{I}^{\circ}$ grau (...) Estabelecido desta forma o parâmetro do "Bem" e do "Mal", para $X$, a vida passa a ter sentido, protegido das "tensões do mundo de ilusões", praticando a leitura da Bíblia (...) Ocorre que $X$ foge também desta comunidade e começa a explicar que houve com esta atitude um afastamento de Deus, e as infrações se repetem, em sua vida cotidiana. O inimigo aparece, arrasta, consome as suas "virtudes" e de novo, hoje com 17 anos e meio na FEBEM (...) X perde-se e esconde-se impotente diante da convivência na FEBEM, que, segundo ele, exige uma proximidade com um "passado" presente de "infrator", o qual ele só evitaria pela servidão a Deus (...) X traz uma resposta concreta, o endereço do Senhor Y, Rua --------, a pessoa que vê em condições de ajudá-lo na reconstrução do "ideal de si mesmo" (...) Telegrafamos para o Sr. Y, solicitando seu pronunciamento, considerando ser uma pessoa significativa para $X$ na maioridade, período que encerra a impunidade penal (...) Recebemos um telefonema do Sr. Y que, no diálogo, verbalizou seu interesse por $X$, confirma ter acompanhado o rapaz por três anos aproximadamente (...) Colocamos o atual estágio de $X$, onde vem buscando na figura de Deus uma proposta de "recuperação" e na pessoa do Sr. Y, um elo de ligação

7. Os trechos dos relatórios apresentados foram copiados dos originais. Qualquer dificuldade de compreensão ou erro gramatical deve-se à redação dos mesmos. 
e ajuda em sociedade (...) X foi trazido ao encontro do Sr. Y, onde se percebeu a alegria de ter sido lembrado, estabeleceu-se o diálogo entre eles, havendo neste contato a proposta de ser participante da Comunidade Desafio Jovem, da qual o Sr. Y é fundador. A obra, localiza-se em Santo André, é orientada por uma equipe técnica e monitores, com filosofia de uma educação pelo trabalho, profissionalização e integração à sociedade pelo vínculo empregatício e comercialização dos produtos confeccionados (...) Sr. Y foi consciente clareando junto a X, e a nós como profissional da FEBEM, quanto ao seu limite diante da pessoa de $X$, conscientizando-o da real vontade de mudança de postura em sociedade (...) Foi considerado também o anseio de retorno à liberdade, vinculado a um propósito de nova opção de vida.

\section{Psicólogo:}

Durante situação de entrevista psicológica, o menor apresenta-se de forma espontânea, verbalizando de maneira clara. Mesmo que tenha confirmado o delito e dizendo o porquê tê-lo feito, percebe-se que não possui um julgamento crítico, tendo um pensamento confuso. Notase que está perdido com relação à família, não sabendo nada sobre a localização da mesma: está emocionalmente perturbado. Participa das atividades do Pavilhão, tendo bom relacionamento interpessoal. Utiliza-se de mecanismos de defesa para explicar suas infrações: diz que roubou por necessidade, mas que não estava mais no caminho do crime (sic). Fala muito de religião, achando que é a salvação. Percebe-se que $X$ não vê o limite das coisas, não tem esse limite. Há necessidade que o menor submeta-se a um tratamento adequado à sua problemática.

Psiquiatra:

O examinado, X, 17 anos, às entrevistas psiquiátricas apresentou-se calmo, consciente, orientado globalmente, euprossexia, com bons cuidados de higiene pessoal e vestes em aprumo. $\bigcirc$ pensamento, em geral, exibiu curso, forma e conteúdo íntegros (...) Durante sua internação nesta unidade, apresentou um surto psicótico de conteúdo religioso, com grave alteração das senso-percepções, caracterizada por alucinações visuais e auditivas controlada medicamentosamente. A inteligência foi detectada nos limites inferiores da normalidade (...) A personalidade evidenciou estruturação temática ativa, construída com fantasias de caráter agressivo e adição a drogas psicotrópicas. A morfologia de sua sexualidade esteve compatível com a faixa etária e sua libido sugeriu fixação nas fases oral e anal do desenvolvimento. O juízo mostrou-se insuficiente para sua auto-regulação perante as realidades e objeto interno e externo revelando modelos internalizados bizarros e persecutórios. A crítica foi estereotipada. A afetividade esteve hipotímica, depressiva perante as frustrações e reativa à ansiedade e à angústia. $\bigcirc$ humor demonstrou-se lábil perante situações e evocações de experiências existenciais, as quais chegavam mesmo a desencadear a crise psicótica observada.

\section{Conclusão:}

Considerando tratar-se de ex-menor, atingindo a maioridade em -------, e que conta com o respaldo social e afetivo do Sr, Y, R.G. --------, que se comprometerá dentro dos procedimentos 
legais da Liberdade Assistida de Santo André, no papel de responsável; e encaminhando X, sob orientação diária e contínua de profissionais da obra Desafio Jovem de Santo André, da qual o referido senhor é presidente; somos de parecer favorável ao desligamento do caso desta instituição, a FEBEM.

Nesta decisão, sobre o destino de um menino que já cometeu infração grave (latrocínio) e revela dificuldades sociais e psicológicas (algumas bastante subjetivas), os profissionais não foram muito severos, oferecendo uma oportunidade ao adolescente fora da FEBEM. No exemplo seguinte, a decisão vai no sentido oposto, ou seja, conclui-se que o menino deve ser retido na instituição. Trata-se de "Z", 17 anos, encaminhado à FEBEM em 1986 com um pedido de internação pelo Juiz de Menores de Bragança Paulista, por "situação irregular". $\bigcirc$ diagnóstico foi emitido por um assistente social e um psicólogo:

Z vem de família em que o pai era constante no trabalho honesto, cônscio de suas responsabilidades para com a mãe e irmãos (...) A morte do pai, desestrutura o grupo familiar quando $Z$ tinha 6 anos (tendo 2 irmãos mais velhos e 2 irmãs mais novas). Situação de perda que provavelmente foi traumática em sua história, dadas às circunstâncias em que ocorreu, e o momento de sua vida por que passava, em que as bases de sua personalidade estavam se consolidando. Essa perda aconteceu após um período no qual o genitor se encontrava desequilibrado emocionalmente em função de ter contraído hidrofobia. Desamparada, a mãe aceita a companhia de Senhor D, passando o referido senhor a ocupar um papel decisivo na formação dos filhos de Da. A (...) A postura autoritária de Sr. D anula o papel de Da. A, e o medo físico atinge conseqüentemente as crianças, que se tornam vítimas de uma relação de domínio e exploração. As crianças passam a esmolarem nas ruas até então, Z com 8 anos, é obrigado a roubar com o padrasto, trabalhar como bóia-fria na lavoura, não tendo sido matriculado em escola pública. Analfabeto, sente-se hoje, inferiorizado em relação aos irmãos e lesado em seus direitos sociais (...) Z, com 14 anos, passa a fazer parte de um grupo de jovens, que eram respeitados pela força física e violência, passando a se rebelar contra o padrasto. Trabalhando na lavoura, e prosseguindo na prática anti-social, com a intenção de ajudar a mãe e os irmãos na subsistência. Encontrando no irmão $\mathrm{H}$, de 24 anos, apoio afetivo, passa a se dedicar somente ao trabalho rural, distanciando-se dos grupos marginais e aproximando-se da mãe, visando ampará-la, pois o padrasto é recolhido em cadeia pública (...) Z entende sua institucionalização como conseqüência de atos sociais cometidos anteriormente, pois afirma ter deixado esta prática, por ocasião do afastamento do padrasto, optando pelo trabalho rural (...) A situação de tensões e privação a que esteve exposto desde a tenra idade parece explicar certo apego ao concreto, bem como certa rigidez que se manifesta numa dificuldade de entrar em contato com suas emoções. Nesse sentido, constatamos que necessita manter sua afetividade sob rígido controle, evitando ligar-se de forma mais profunda em seus relacionamentos interpessoais (...) Num clima pouco favorável a seu desenvolvimento emocional, parece que $Z$ estruturou sua personalidade de modo a defender sua integridade egóica pela não exteriorização de afetos, devido a um ambiente hostil e perigoso. No entanto Z mostra-se autoconfiante no sentido de procurar mudanças em seu meio externo, por uma conduta construtiva de sua parte, visando assim melhoras 
de sua realidade. Em seu projeto de vida, procura preservar o vínculo com sua mãe e com os irmãos (que se colocam como figuras significativas e estáveis), sendo que se imagina no futuro de maneira positiva e realista, mantendo-se próximo destas figuras. Sente-se amado e reconhece-se útil enquanto mão-de-obra, auxiliando na manutenção do lar. Durante a entrevista, Z mostrou-se disponível ao nosso contato, relatando sua história de vida de forma tranquila e sem resistência.

Conclusão:

Diante do exposto, considerando-se o pedido de internação do MM.J. de Bragança Paulista/SP, além de seu despreparo educativo e profissional, somos favoráveis à sua internação na UE-3 onde um trabalho integrado à terapia, educativo e profissionalizante possam melhor instrumentalizá-lo quando de seu retorno ao convívio familiar, bem como auxiliá-lo na criação de uma auto-imagem fortalecida, positiva e construtiva.

Comparativamente, o parecer técnico do primeiro adolescente ("X") mostra comprometimentos sérios (principalmente psicológicos) e uma conclusão compreensiva que decide liberá-lo. Quanto ao segundo, o diagnóstico parece justificar e explicar, de forma favorável, a situação do adolescente. Porém, a sentença é extremamente severa. Nesse contexto poderiam ser lançadas algumas questões: por que apenas " $X$ " foi liberado? Será que é porque alguém assume a responsabilidade do adolescente, oferecendo-lhe um apoio conforme as normas sociais? Essa seria uma razão suficiente para convencer os profissionais e, sobretudo, o juiz no que diz respeito à liberação?

Em relação ao segundo caso ("Z”), será que o pedido de internação por parte do juiz influenciou a decisão? A equipe não teria autonomia, após o estudo do caso, para contestar esse pedido? A internação é surpreendente, visto que o relatório não indica graves problemas familiares ou psicológicos no momento em que o adolescente foi detido. Ao contrário, o menino parece estar integrado no meio familiar e colaborar para a sua manutenção por meio do trabalho rural. Por que, então, não permitir a esse jovem, que cometeu somente infrações leves, permanecer com sua família ou estar eventualmente em liberdade assistida, caso se suspeite que ele ainda possa cometer algum delito? A decisão de submeter o menino a um trabalho "terapêutico, educativo e profissional" não está mascarando um julgamento moral e social dessa família que não é considerada suficientemente capaz de assegurar a educação e a profissionalização do adolescente?

A análise proposta em seguida tenta refletir sobre esse conjunto de questões. Primeiramente, serão apontados alguns pressupostos teóricos, para tentar fundamentar a temática dos "diagnósticos institucionais". Finalizando, a terceira parte aborda os discursos dos próprios profissionais das equipes da FEBEM-SP, que explicitam as idéias subjacentes aos relatórios escritos. 


\section{DIAGNÓSTICOS PSICOSSOCIAIS: EXIGÊNCIAS DA INSTITUIÇÃO E AUTONOMIA NAS PRÁTICAS PROFISSIONAIS}

Serão ressaltados aqui alguns autores e correntes teóricas que introduziram análises relevantes para o estudo dos diagnósticos psicossociais. Essas reflexões têm como ponto de partida os estudos de Castel (1976; 198I) sobre instituições psiquiátricas, os quais oferecem uma contribuição importante para a compreensão das atividades dos especialistas do ponto de vista sociopolítico. Na seqüência, as práticas profissionais serão abordadas numa perspectiva microssocial, em que os protagonistas estão inseridos em contextos específicos, podendo ser entendidos por suas interações e representações. Com esse objetivo, este estudo apoiar-se-á na corrente interacionista do desvio e na teoria das representações sociais, passando pelo conceito de habitus de Bourdieu.

A análise de Castel (1976) sobre a medicina psiquiátrica na França, no século XIX, introduz reflexões essenciais sobre as funções sociais das instituições, ressaltando o papel do saber dos especialistas nesse contexto. Para o autor, a instituição (psiquiátrica, no caso) foi criada para segregar, rotular e tratar determinadas populações, contando com a contribuição técnico-cientíica dos profissionais para legitimar essa situação. $\bigcirc$ autor chama a atenção para a lógica de subjetivização que caracteriza o conjunto das intervenções dos trabalhadores sociais, conferindo-lhes um sentido político.

Castel, que expressa uma inspiração foucaultiana, insiste sobre o poder dos especialistas em decidir o tratamento e o controle social de certas populações, afirmando que há um discurso político e social no interior do discurso técnico-científico. $\bigcirc$ autor percebe as ava-liações dos profissionais como estratégias de tratamento dos problemas sociais a partir da gestão das particularidades do indivíduo:

Um especialista não é, e não tem de ser um teórico. $\bigcirc$ que o determina é menos a força do verdadeiro do que a necessidade de ajustar os elementos conflitantes de uma situação concreta. São passados a ele o caráter mais ou menos aproximativo de suas avaliações na medida em que ele ocupa uma posição estratégica num processo de decisão. (Castel, 1976, p. I 54)

Para Castel, a ideologia científica mascara as funções sociais da instituição. Em trabaIho posterior ( $198 \mathrm{I})$, o autor refere-se aos diagnósticos como um procedimento no qual as decisões dos especialistas podem ser legitimadas pela sociedade. $O$ papel político exercido pelo saber técnico-cientíico dos especialistas manifesta-se nesses diagnósticos, que, sem fins propriamente terapêuticos, acabam expressando a objetivação de uma diferença entre populações e construindo um perfil específico:

Uma orientação diferente desenvolve-se a partir de uma transformação dos dispositivos médico-psicológicos que, autorizando uma dissociação radical entre o diagnóstico e o atendimento, 
faz balançar a prática terapêutica para o lado de uma pura atividade de experts. O saber médicopsicológico torna-se dessa forma o instrumento de uma política de gestão diferencial das populações, mais do que de cuidados. (Castel, I98।, p. I I5)

Embora Castel insista sobre a dimensão sociopolítica das práticas profissionais na instituição, não as dissocia do conjunto de idéias dos especialistas, mencionando o "imaginário profissional" como um "sistema particular de representações, diríamos quase de crenças" (1981, p. 102). Porém, seu centro de interesse é o contexto sociopolítico em que a instituição está inserida, e que leva à legitimação de um determinado desvio. Já a corrente interacionista, inspirada no interacionismo simbólico, preocupa-se mais com a maneira que esse desvio é construído.

O interacionismo simbólico privilegia a concepção que os atores fazem do mundo social, o qual é estudado pelo sentido que atribuem aos objetos, aos indivíduos, aos símbolos que os rodeiam. Uma das principais perspectivas de análise no interacionismo simbólico é a labeling theory (teoria da "rotulação" ou da "designação"), desenvolvida principalmente por Becker (1985). Como observa Coulon:

Segundo a teoria da rotulação, o desviante é aquele que é designado como tal, e não existe consenso que definiria claramente o que é a violação de uma norma, ou mesmo o que constitui uma norma, no interior das sociedades complexas modernas. Ser designado como desviante resulta, de fato, de uma grande variedade de contingências sociais, influenciadas pelos que têm o poder de impor essa designação: tornamo-nos aquilo que é descrito sobre nós. (Coulon, 1992, p. 122)

Becker interessa-se "menos pelas características pessoais e sociais dos desviantes do que pelo processo, ao termo do qual, eles são considerados estranhos ao grupo, assim como por suas reações a esse julgamento" (1985, p.33). Para o autor, o desvio é o " produto de uma transação efetuada entre um grupo social e um indivíduo que, aos olhos do grupo, transgrediu uma norma" (1985, p.33). A concepção de Becker sobre o fenômeno do desvio privilegia o papel da ação coletiva, cujas regras seriam impostas por um processo social que define coletivamente certas formas de comportamento como problemáticos.

Nessa perspectiva interacionista, a moralidade de uma sociedade é socialmente construída, sendo relativa aos atores, ao contexto social e a um determinado momento histórico. O caráter desviante ou não de um ato depende, portanto, da maneira pela qual os outros reagem diante dele.

Uma das principais contribuições dos trabalhos de Becker foi mostrar que o desvio é o resultado das iniciativas do outro. Quando certos indivíduos são definidos coletivamente como desviantes, aparece uma nova categoria de problema social, encadeando um processo de intervenção empreendido para selecioná-los, identificá-los e tipificá-los. 
Por isso, aparecem os métodos de controle e a institucionalização do "tratamento" desses indivíduos.

Becker ressalta o papel dos agentes que contribuem para a definição do desvio. Para o autor, esse fenômeno liga estreitamente "a pessoa que emite o julgamento do desvio, o processo que chega a esse julgamento e a situação dentro da qual ele é produzido"(Becker, 1985, p.28). É nesse contexto que ele situa os especialistas e os serviços profissionais: "é de maneira seletiva que os representantes da lei, respondendo às pressões de sua própria situação de trabalho, aplicam a lei e criam categorias de pessoas estranhas à coletividade" (1985, p. 185).

Seria importante salientar que os profissionais que trabalham em instituições não têm propriamente o papel de criar desviantes. $O$ desvio primário existe antes da entrada do indivíduo na instituição. Os especialistas, na realidade, estão envolvidos com o desvio secundário, que é a amplificação do primário, podendo não exatamente criar, mas participar da construção e da legitimação de um desvio pré-existente à institucionalização.

Para Becker, julgar uma categoria de pessoas como estranhas à coletividade implica um certo poder, que é legitimado pela organização política e econômica. E o sucesso do processo de rotulação reside nesse poder:

...uma vez que existe uma norma, é preciso que ela seja aplicada a determinados indivíduos (...) É preciso descobrir os delinqüentes, identificá-los, apreendê-los e provar sua culpabilidade (...) Essa tarefa incumbe, comumente, aos profissionais especializados, a imposição do respeito às normas; são eles que, fazendo aplicar as normas preexistentes, criam uma categoria específica de desviantes, estranhos à coletividade. (Becker, 1985, p. I86)

Becker afirma que o processo de intervenção sobre o outro representa uma desigualdade entre atores. Os especialistas, por meio de suas ações e representações, estão autorizados a definir o status social e o futuro das pessoas que eles avaliam. As teorias interacionistas do desvio, particularmente a labeling theory, avançam em reflexões fundamentais no sentido de chamar a atenção para as conseqüências do fato de um indivíduo ser rotulado como desviante. Segundo Becker, fica mais difícil prosseguir as atividades comuns da vida cotidiana, e essas dificuldades podem incitar o indivíduo a ações "anormais".

Bourdieu dirige algumas críticas às teorias interacionistas. Por privilegiar as construções da experiência humana, sem evocar como elas foram construídas historicamente, o autor menciona que o interacionismo tende a se aproximar de uma visão subjetivista que permanece redutora. Essa corrente dá prioridade ao processo em que os agentes apreendem o mundo social e constroem suas visões de mundo. Para Bourdieu, esse contexto ocorre por meio de pressões estruturais, geralmente negligenciadas pelo pensamento interacionista (Bourdieu, 1987). 
Com o conceito de habitus ${ }^{8}$, o autor tenta articular as estruturas internas da subjetividade e as estruturas sociais externas. De acordo com Accardo e Corcuff, Bourdieu insiste em que as estruturas subjetivas, ou as representações são construídas a partir da interiorização das estruturas objetivas:

Sistema de disposições para agir, perceber, sentir e pensar de uma certa maneira, interiorizados e incorporados pelos indivíduos no decorrer de suas histórias, o habitus se manifesta fundamentalmente pelo sentido prático, ou seja, a aptidão para se mover, agir e se orientar de acordo com a posição ocupada no espaço social, de acordo com a lógica do campo e da situação dentro da qual estamos implicados. (Accardo, Corcuff, 1989, p.66-7)

conceito de habitus permite situar as representações dos agentes numa relação dialética entre as estruturas objetivas e as subjetivas. Bourdieu afirma que o habitus (princípios inconscientes de ação e reflexão, de esquemas de sensibilidade e de entendimento) é estruturado pelas condições sociais de existência. Depois dessa estruturação, ele continua produzindo percepções, representações, opiniões, crenças, gostos, desejos, enfim, toda uma subjetividade que passa a ter interdependência relativamente ao exterior. Essa subjetividade expressa-se e exterioriza-se na ação dos indivíduos e dos grupos, contribuindo para produzir e reproduzir as estruturas sociais e as instituições. E as estruturas sociais e as instituições, por sua vez, se impõem aos indivíduos e grupos como condições objetivas de existência (Bourdieu, 1987). De acordo com o autor:

....sistema adquirido de esquemas geradores, o habitus torna possível a produção livre de todos os pensamentos, todas as percepções e todas as ações inscritas nos limites inerentes às condições particulares de sua produção, e delas somente. Por ele, a estrutura que o produz governa a prática, não segundo as vias de um determinismo mecânico, mas pelas pressões e limites originariamente atribuídos a suas invenções. (Bourdieu, 1980, p.92)

A contribuição de Bourdieu fundamenta as reflexões sobre as representações sociais ${ }^{9}$, apresentadas em seguida. Serão privilegiados alguns aspectos essenciais para compreensão do sistema de idéias dos profissionais, ressaltando as práticas dentro das quais se insere, evidentemente, a elaboração de diagnósticos.

8. A teoria do habitus, elaborada por Bourdieu, emerge de uma série de estudos realizados pelo autor a partir dos anos 60. Trata-se de uma tentativa, cujo aprofundamento não será abordado aqui, de operacionalizar uma síntese de diferentes correntes filosóficas e sociológicas. Bourdieu tenta confrontar e articular autores que seguem correntes teóricas diferentes. A sua finalidade essencial é evitar a oposição entre o individual e o social, articulando subjetividade com objetividade.

9. A noção de "representação social" foi retomada da sociologia durkheimniana pelo psicólogo social Serge Moscovici, em trabalho publicado na França nos anos 60 (La psychanalyse, son image, son public), ver Moscovici, 1976. A partir dessa data, abriu-se uma área de estudos sobre as representação sociais (que não será aprofundada neste texto). Vários autores e pesquisas começaram a ser divulgados, com abordagens das representações sociais em diversas dimensões (cognitiva, social, afetiva, experimental) e em diferentes temas (criança, saúde, escola, profissões...). 
Jodelet (1993) refere-se às representações sociais como um ato de pensamento pelo qual um sujeito se relaciona a um objeto. Elas correspondem, portanto, a um processo de apropriação da realidade externa, pelo pensamento, e à elaboração psicológica (cognitiva e afetiva) e social (contexto ideológico, histórico, inserção social do indivíduo) dessa realidade. $\bigcirc$ produto da representação vai se manifestar no real, pela ação dos indivíduos.

A autora menciona as representações sociais como sistemas de interpretação que regem nossa relação com o mundo e com os outros, orientando e organizando as condutas e as comunicações sociais. Segundo Jodelet, elas "estão ligadas a sistemas de pensamento mais amplos, ideológicos ou culturais, a um estado de conhecimentos científicos, assim como à condição social e à esfera da experiência privada e afetiva dos indivíduos" (1993, p.35).

Um aspecto essencial das representações sociais é que veiculam uma série de elementos (informativos, cognitivos, ideológicos, normativos, crenças, valores, atitudes, opiniões, imagens, etc) que estão sempre organizados sob a forma de um saber que diz algo sobre o estado da realidade (Jodelet, 1993). Trata-se de um saber que se distingue do saber científico, sendo chamado de "saber do senso comum" ou "saber ingênuo", "natural". Porém, ele é fundamental na dinâmica da vida social porque esclarece os processos cognitivos e as interações sociais. Jodelet define uma representação social como um "forma de conhecimento, socialmente elaborado e compartilhado, que possui um objetivo prático e participa da construção de uma realidade comum a um conjunto social” (1993, p.36).

Segundo Moscovici, cada vez que um saber é gerado e comunicado, ele se torna parte da vida coletiva: " representando-se uma coisa ou uma noção, não se faz unicamente suas próprias idéias e imagens. Gera-se e transmite um produto progressivamente elaborado em inumeráveis lugares, segundo regras variadas" (1993, p.83). O autor ressalta que as representações sociais, ao mesmo tempo geradas e adquiridas, não têm necessariamente um caráter preestabelecido e estático.

Reconhece que o indivíduo sofre a pressão das representações dominantes na sociedade quando pensa ou expressa seus sentimentos. Essas representações, morais ou intelectuais, diferem de acordo com a sociedade em que nascem e são trabalhadas. Porém, sendo produzidas numa realidade prática e fazendo parte de um contexto sociopolítico, ao mesmo tempo que resultam dele, têm autonomia para modificá-lo. Moscovici assinala que as representações são sociais não somente porque têm um objeto comum a um grupo de indivíduos ou a uma sociedade, ou porque são compartilhadas. Elas são sociais também porque expressam o produto de uma divisão do trabalho que as marca de uma certa autonomia. É nesse contexto que podem ser inseridas as práticas profissionais:

Sabemos que existe uma certa categoria de pessoas que têm por ofício fabricá-las (as representações sociais). São todos aqueles que se consagram à difusão de conhecimentos científicos e artísticos: médicos, terapeutas, trabalhadores sociais, animadores culturais, especialistas das 
mídias e do marketing político. Sob muitos olhares, eles se aparentam aos fazedores de mitos das civilizações antigas. Seu savoir-faire é codificado e transmitido, conferindo àqueles que o possuem uma autoridade certa. Seria preciso atribuir mais atenção a essa divisão do trabalho e aos especialistas que colocam em prática os métodos que supõem um conhecimento da vida psíquica e uma visão do aspecto coletivo... (Moscovici, 1993, p.84)

Finalizando essas reflexões teóricas, percebe-se que as representações sociais dos especialistas contêm elementos do senso comum que se manifestam em suas práticas. $\bigcirc$ discurso científico que eles expressam mascara o discurso sociopolítico que emerge da sociedade e das instituições em que eles estão inseridos. Dependendo da forma como são elaboradas no pensamento e transmitidas nas práticas, essas representações podem participar da reprodução ou da mudança, tanto das próprias práticas profissionais quanto das instituições. Esse tema será ilustrado em seguida, ao serem explicitados alguns discursos dos profissionais da FEBEM-SP, relacionados aos diagnósticos psicossociais.

\section{DISCURSOS DOS PROFISSIONAIS DA FEBEM-SP SOBRE OS DIAGNÓSTICOS ${ }^{10}$}

Como observa Chabrol: "os discursos recolhidos numa pesquisa parecem-nos marcados, como todo discurso, pela situação histórica, as circunstâncias reais ou imaginadas de sua produção e os papéis psicossociais reais ou imaginários dos protagonistas" ( 1982, p. I07).

Por meio de três exemplos ("discurso não-crítico", "discurso moderado", discurso "crítico") será demonstrado que as idéias dos especialistas, presentes nos diagnósticos psicossociais que emitem, relacionam-se a suas concepções sobre a criança ou o adolescente, sobre a FEBEM, e sobre a própria atividade profissional. Há um certo encadeamento de idéias comuns que se articulam nos quatro temas, e que, certamente, influenciarão na decisão tomada a respeito de cada criança ou adolescente.

Discurso não crítico: tendência aprovativa e conformista para com a FEBEM-SP'I

Esse tipo de discurso é, basicamente, marcado pela tendência em tratar o "caso individual", pela avaliação e definição psicológica da criança ou do adolescente e da apreciação de seu ambiente sociocultural. As dificuldades da criança ou do adolescente são

10. A análise completa dos dados, apresentada na tese de doutorado que inspirou este artigo, inclui primeiramente a análise de conteúdo de cada um dos quatro temas-chave que emergiram nos discursos dos 30 profissionais entrevistados: "criança ou adolescente", "FEBEM", "atividade profissional”, "diagnóstico". Após a análise de cada tema no conjunto dos discursos, foi observado o encadeamento dos quatro temas nos discursos individuais. Serão mencionados neste artigo somente alguns elementos referentes a essa segunda etapa, utilizando-se três exemplos de discursos, para tentar mostrar como se fundamentam as opiniões dos especialistas sobre os diagnósticos psicossociais.

I1. O modelo apareceu no discurso de dez profissionais, dos 30 entrevistados. 
freqüentemente relacionadas ao aspecto biológico (ligado à constituição do indivíduo), aos distúrbios psicológicos e às dificuldades sociofamiliares (relacionadas essencialmente à pertença de classe). A FEBEM é percebida de forma positiva, sendo valorizada, no sentido de poder inculcar as normas sociais dominantes. As práticas profissionais, em geral, são exercidas com satisfação, obedecendo ao objetivo da instituição de ensinar valores, disciplina e gosto pelo trabalho. Chabrol encontra posicionamento semelhante ao analisar as práticas de um centro de reeducação para jovens delinqüentes na França:

Como todo locutor/manipulador dispondo de um poder social de pressão importante, o educador (ou o instrutor, às vezes) não pode-se contentar com uma conformidade somente no nível dos atos ou do fazer fazer. Ele tenta também agir sobre o ser do jovem. Ele quer fazê-lo ser de outra maneira. (1981, 154)

Nesse modelo de discurso, as críticas sociais e institucionais, assim como as autocríticas sobre o próprio trabalho estão praticamente ausentes. Os trechos da entrevista mencionados em seguida ilustram essa posição:

Criança ou adolescente -...é alguém manipulável, alguém que não tem identidade própria... se a gente fala do menor infrator é bem isso. Ele é manipulado, influenciado, ele segue a cabeça dos outros... Como na adolescência o grupo é muito importante, a família fica em segundo lugar (...) Para a gente o trabalho com as famílias é muito importante. Não adianta nada preparar o menino e devolvê-lo a essa família doente, ele vai voltar aqui, os sintomas vão voltar...

FEBEM - Os menores são usados pelos maiores na área do crime... eles dizem ao menor "você fica aqui alguns meses e depois você sai, e eu vou para a cadeia"... Então a FEBEM é uma prisão de chocolate (...) Se a gente fala da instituição, é muito complexo, muito geral... Eu não penso na instituição. Eu penso em mim, enquanto pessoa, trabalhando numa instituição. Eu estou mais preocupada com o meu próprio trabalho.

Atividade profissional -...uma das coisas que eu mais faço é trabalhar com a auto-valorização deles... porque eles são umas "cacas", né? ainda mais quando eles sabem que têm Aids... Meu trabalho é a automotivação, a valorização, é orientar para que eles façam planos de futuro, para que eles se descubram...

Diagnóstico psicossocial - ...o menino fica algum tempo aqui para que a gente o conheça... a gente vê a família, onde eles moram... a gente convoca a família para orientá-la, a gente diz à mãe o que o menino vai fazer durante o tempo em que ele está aqui... Então, a gente fecha melhor o caso com a família.

[F, 33 anos, casada, psicóloga, unidade de encaminhamento para infratores ( | 4- | 8 anos), profissão do pai não declarada, mãe do lar, cônjuge monitor na FEBEM, posição política não declarada, três anos e seis meses na FEBEM] ${ }^{12}$

12. Os dados socioprofissionais dos especialistas serão mencionados a título ilustrativo. Não cabe neste artigo uma análise detalhada que associe tais informações aos discursos. Esse tema é abordado na tese que originou o artigo, em que são propostos três perfis de profissionais das equipes da FEBEM, nas quais são articuladas as características pessoais e socioprofissionais aos conteúdos dos discursos. 
A decisão que define o que acontecerá com a criança ou com o adolescente apóiase nesse conjunto de idéias. Os diagnósticos psicossociais são percebidos de maneira conformista, na medida em que eles aparecem como um dispositivo natural e rotineiro no atendimento proposto pela FEBEM-SP. Não há sinais de uma consciência sobre o poder dos profissionais que emitem diagnósticos, no que diz respeito a decidir o futuro da população recebida, avaliada e encaminhada pela instituição.

Discurso moderado: visão preventiva e assistencialista em relação ao atendimento proposto pela FEBEM-SP'3

Esse tipo de discurso apresenta alguns elementos conflitantes e ambíguos. As críticas à sociedade geralmente são fragmentárias e acompanhadas pela valorização do papel preventivo e assistencialista da FEBEM-SP, vista como um meio de oferecer uma solução imediata e provisória à situação socioeconômica precária das crianças e dos adolescentes ${ }^{14}$. Sendo percebida, em alguns momentos, como se estivesse dissociada da sociedade, a instituição é considerada como uma espécie de "reparação" dos efeitos perversos dessa mesma sociedade. As práticas profissionais são também encaradas como uma forma de ajuda, muitas vezes de fundo humanitário e cristão, no momento em que a criança ou o adolescente se encontram institucionalizados. Em geral, elas não são inseridas no espaço social mais amplo. $\bigcirc$ exemplo abaixo ilustra esse tipo de discurso:

Criança ou adolescente -...Essa criança, para mim, deveria ter o direito de ter tudo o que os outros têm... ela deveria ser mais valorizada, ela deveria ter seu espaço fora e não deveria precisar vir para cá... Eu penso que ela deveria estar com sua família, que tem também o direito de ter onde morar, o que comer, onde trabalhar...

FEBEM -...A gente deve tentar mostrar às pessoas que a FEBEM tem o lado negativo, mas também o positivo... Eu acho que o positivo deveria ser mais valorizado, porque existem bons trabalhos na FEBEM e que não são nem mesmo ouvidos...

Atividade profissional - Hoje eu sou responsável pelo setor técnico. Minha tarefa principal é coordenar os trabalhos que tornam possível encontrar uma linha de trabalho na unidade... Eu devo motivar para que o trabalho seja interdisciplinar, para que os profissionais trabalhem os casos no seu conjunto (...) Aqui não é nenhuma maravilha, mas a gente tenta transmitir à criança o que a gente tem de melhor, para que quando ela saia daqui leve pelo menos um caminho para seguir lá fora, e que isso seja o melhor para ela.

Diagnóstico psicossocial- ... . estudo de caso precisa todo o processo dessa criança, nos níveis

13. O modelo apareceu no discurso de II profissionais, dos 30 entrevistados.

14. Seria importante salientar que nesse grupo se concentra a maioria dos profissionais que trabalham em estabelecimentos para crianças e adolescentes "abandonados". Essa preocupação em resolver a dificuldade imediata desses indivíduos parece, portanto, natural. Porém, é necessário observar se esse "imediato" não está se tornando "perene", o que comprometeria a eficiência da instituição diante dos problemas sociais. 
social, psicológico, médico e pedagógico. Nós damos bastante importância a isso... Tem crianças de quatro ou cinco anos que falam de sua história, e é importante registrar isso, e, principalmente, é preciso saber o que a gente escreve porque essa criança carregará isso por toda sua vida. É preciso tomar cuidado para não ter somente uma impressão dessa criança e dessa família, e rotulá-los. Eu acho que o estudo de caso deve ser muito bem-feito.

[F, 32 anos, casada (um filho), assistente social, unidade de triagem para crianças abandonadas ( 0 a 6 anos), pai corretor de imóveis, mãe do lar, cônjuge professor de tênis, Partido dos Trabalhadores - PT -, sindicato dos assistentes sociais, I I anos e 6 meses na FEBEM]

De acordo com esse depoimento, percebe-se uma concepção crítica das desigualdades e das injustiças sociais que afetam as crianças e os adolescentes das classes desfavorecidas no Brasil. Porém, as práticas, especialmente os diagnósticos psicossociais, estão centralizadas na ajuda individual no momento em que esses indivíduos se encontram na instituição. Aparece uma consciência sobre a importância do estudo de caso e são mencionados os cuidados necessários para a realização de um diagnóstico detalhado e multidisciplinar. Mas será que é possível fazê-lo dessa maneira, na realidade institucional? Se não existe acompanhamento e supervisão posteriores, articulando ajuda individual a questões sociais mais amplas, qual seria a sua eficiência? Por exemplo, os diversos estudos de casos realizados nos estabelecimentos para "abandonados" poderiam contribuir para que essa criança ou esse adolescente não se tornasse posteriormente um "infrator"?

Discurso crítico: abordagem das questões políticas

e socioeconômicas mais amplas ${ }^{15}$

Esse modelo de discurso apresenta um encadeamento de idéias críticas, que aparecem nos quatro temas-chave. Ele expressa uma visão crítica da estrutura social brasileira e dos preconceitos que vitimam as crianças e os adolescentes das classes populares. A FEBEM é vista como ineficiente para ajudar e melhorar as condições de vida desses indivíduos. Esse modelo de discurso também coloca em questão a realidade política e econômica do país, inserindo nesse contexto os obstáculos do exercício profissional na realidade concreta. Emergem queixas quanto às dificuldades em trabalhar na FEBEM e resistências em aceitar o poder institucional, do qual os próprios especialistas fazem parte. Nesse sentido, o sentimento de ambigüidade e as autocríticas são freqüentes. Os trechos seguintes expressam esse ponto de vista:

Criança ou adolescente -... $\bigcirc$ infrator tem mais dignidade, o abandonado não tem muita... $\bigcirc$ abandonado é mais o cara que diz "sim" a tudo. Se você bate nele, ele diz "obrigado", se você dá um doce para ele, ele diz "obrigado". O infrator, não... Ele tem uma posição mais marcante, ele te enfrenta, ele discute com você, ele questiona suas idéias...

15. Esse modelo apareceu no discurso de nove profissionais, dos 30 entrevistados. 
FEBEM - Na maioria dos casos, a gente tenta favorecer a saída do cara dessa história... "não more na FEBEM. More na rua!"... porque eu acho que a FEBEM não faz nada de bom. O que ela chega a fazer é um mero acaso. Ela atrapalha muito mais (...) A FEBEM sai de uma reflexão sobre o "menor" para estar mais próxima do confinamento. Sua preocupação é confinar...

Atividade profissional-A gente sente o papel do psiquiatra nessa instituição... agora eu falo do que eu sinto, do que eu tento desenvolver mais... é muito amplo, o psiquiatra deve ser malandro, é um papel muito mais do lado humanista, da verdadeira clínica psiquiátrica... é tentar lutar contra a própria instituição para ter melhores condições para os que estão aqui...

Diagnóstico psicossocial - ... O diagnóstico representa antes de tudo a farsa da instituição, sua mentira... é um espaço onde a gente escreve as questões do senso comum em relação ao "menor", ao infrator. Mas a gente não escreve isso como sendo a nossa opinião: "que eles se danem, que eles fiquem em cana"... A gente escreve tudo isso em termos técnicos, a gente faz avaliações e testes carregados de preconceitos. Às vezes, eu tenho uma opinião formada, eu sei o que vai acontecer... O diagnóstico tem o papel de esconder todo esse jogo, porque, na verdade, é um jogo de cartas marcadas; na verdade, ele vai no sentido de colocar o menino fora de circulação...

[H, 4 I anos, casado (dois filhos), psiquiatra, divisão de saúde, pai técnico em indústria de tecelagem, mãe do lar, cônjuge do lar, Partido Comunista Brasileiro - PCB ${ }^{16}$, sindicato dos médicos, seis anos e seis meses de trabalho na FEBEM]

No conjunto do discurso crítico, o diagnóstico mostra-se como um dispositivo incapaz de trazer uma mudança significativa quanto às dificuldades apresentadas pelas crianças e adolescentes. Considerando-se as condições institucionais e sociais, torna-se difícil um parecer que possa contribuir para minorar essas dificuldades e favorecer a integração desses indivíduos na sociedade. $\bigcirc$ diagnóstico assume mais o papel de segregar do que ajudar terapeuticamente e contribuir para a inserção social. Sob esse ponto de vista, longe de propor soluções concretas e acompanhamento, as decisões sobre cada caso, freqüentemente, não evitam as recidivas, a prisão na maioridade, ou a morte prematura. Com essa concepção de traço pessimista, que descreve a realidade das práticas da maneira que ela é percebida na dinâmica institucional, uma questão poderia ser levantada: será que existe uma saída para evitar essa situação e melhorar a qualidade do atendimento da FEBEM?

Para concluir, poderiam ser lançadas algumas questões e sugestões para reflexão, sem, evidentemente, intenção de prescrever um atendimento ideal. No caso da FEBEM, como seria possível amenizar o caráter burocrático-administrativo, às vezes necessário devido ao número elevado de crianças encaminhadas diariamente à instituição? Descentralizar, instalando vários estabelecimentos que recebessem um número menor de crianças e adolescentes, compatível com a capacidade de atendimento das equipes, seria uma solução

16. Em 1989, ano eleitoral em que foi realizada essa pesquisa, o PCB tinha Roberto Freire como candidato à Presidência da República. 
possível e viável? Sem essa alternativa, como reduzir as incertezas de um diagnóstico apressado e imediato? Como preparar tecnicamente os profissionais para a realização desses diagnósticos? Como acompanhar as decisões que estão em cada diagnóstico, para avaliar e supervisionar seus resultados?

$\bigcirc$ material proposto nesse artigo introduz algumas reflexões que podem ajudar a discutir as questões colocadas acima. Por um lado, a crítica ao funcionamento judiciárioinstitucional, em que os casos são passados de uma esfera a outra, de forma burocrática e geralmente descontínua, é um aspecto importante a ser enfrentado. Por outro lado, a autocrítica das práticas por parte dos profissionais seria também um elemento fundamental. Refletir sobre a própria formação, sobre questões éticas, sobre suas visões de mundo poderia levá-los a perceber como estão exercendo a autonomia inerente a suas práticas: se estão adotando uma postura crítica e autocrítica, participando de um processo de mudança que possibilite a melhora da qualidade do atendimento da FEBEM, ou se estão contribuindo para reproduzi-la.

\section{REFERÊNCIAS BIBLIOGRÁFICAS}

ACCARDO, A., CORCUFF P. La Sociologie de Pierre Bourdieu: textes choisis et commentés. Bordeaux: Mascaret, 1989.

BECKER, H.S. Outsiders. Paris: A.M. Metailié, 1985.

BOURDIEU, P. Choses dites. Paris: Minuit, 1987. . Le Sens pratique. Paris: Minuit, 1980.

CASTEL, R. La Gestion des risques. Paris: Minuit, 1981. . L'Ordre psychiatrique: l'âge d'or de l'aliénisme. Paris: Minuit, 1976.

CEREZUELLE, D. La Perte de l'écrit en institution éducative: handicaps et inadaptations. Les Cahiers du C.T.N.E.R.H.I., n. 22, p. 9-18, 1983.

CHABROL, C. A qui parle-t-on dans un entretien d'enquête? Connexions, n. 38, p. I07-2I, 1982.

. Réflexions sur des discours de travailleurs sociaux, Connexions, no. 33, p. I4959, 1981 .

COULON, A. L'École de Chicago. Paris: P.U.F., 1992. (Col. Que sais-je?)

FEBEM-SP. Relatório anual de atividades, 1989, p. I0. mimeo. . Fechamento do Boletim Diário de Lotação. 21 mar. 1989. . Fechamento do Boletim Diário de Lotação. 30 nov. 1989. 
ION, J., TRICART J.-P. Les Travailleurs sociaux. Paris: La découverte, 1987.

JODELET, D. Les Représentations sociales, Paris: P.U.F., 1993. Représentations sociales: um domaine en expansion, p.3|-6I.

LIMA, R.C.P. Le Processus d'élaboration de diagnostics sur les enfants et adolescents "abandonnés", "assistés" et "infracteurs" par les équipes interdisciplinaires de la Fondation de l'État du Bien-Être du Mineur de São Paulo (FEBEM-SP.) - Brésil. Tese (dout.) Univ. René Descartes. Sorbonne, 1994.

MOSCOVICI, S. Des Représentations collectives aux représentations sociales. In: JODELET, D. (org.). Les Représentations sociales. Paris: P.U.F., 1993. p.62-86. . La Psychanalyse: son image, son public. 2.ed. Paris: P.U.F., 1976. 
